Available online on 15.9.2018 at http://ujpr.org
Universal Journal of Pharmaceutical Research
An International Peer Reviewed Journal
Open access to Pharmaceutical research

\title{
THE IMPACT OF STRATEGIC FACTORS OF WASTE MANAGEMENT ON ENVIRONMENTAL PROTECTION IN KAZEROON CITY IN 2017 Mohammadrafi Mehbodi $^{1}\left(\mathbb{D}\right.$, Abbas $_{\text {Yazdanpanah }}{ }^{1}\left(\mathbb{D}\right.$, Jamalledin Alvaani $^{2}(10)$ ${ }^{1}$ Department of Healthcare Management, Marvdasht Branch, Islamic Azad University, Marvdasht, Iran. ${ }^{2}$ Department of Psychology, Marvdasht Branch, Islamic Azad University, Marvdasht, Iran.
}

\section{ABSTRACT}

Objective: Today, environment protection is one of main pillars of observing human right, so that protection and maintenance of environment is one of main duties of present and future. After investigating and identifying environmental factors including internal and external environment of waste management and preparing a list of the most important strengths and weaknesses, opportunities and threats ( 40 factors) and selecting the most important factors participatory ( 24 factors) using EFE and IFE matrix. Methods: Factors were analyzed and evaluated and the score was determined and in the following, using the matrix and regarding internal and external factors, the most suitable strategies were introduced for optimal management of waste system of the studied region and in the next stage, using the matrix score of evaluating internal and external factors and strategies of matrix formation matrix, the present status of the organization (IE), the preservative approach was selected as goal approach and attraction of any preservative strategies was specified in the qualitative strategic planning matrix (QSPM).

Results: On the basis of results should be said that the order of approaches priority is based on their so-called genera weight rate and movement towards sustainable development that based on the attraction score, the priorities became in this order that the first priority is related to strategy and then respectively optimizing various stages of wastes management.

Conclusion: In conclusion, by increasing awareness and changing the individuals attitude towards correct method of waste management like reduction of waste production, separation of recyclable materials at home and method of collecting through holding training classes, preparing and distributing advertising posters in the cities, implementing plan of separation from origin and its success requires public participation and cooperation.

Keywords: Environment, strategy, waste management.

Article Info: Received 18 July 2018; Revised 29 July; Accepted 26 August, Available online 15 September 2018

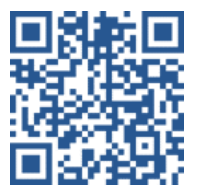

\section{Cite this article-}

Mehbodi M, Yazdanpanah A, Alvaani J. The impact of strategic factors of waste management on environmental protection in Kazeroon city in 2017. Universal Journal of Pharmaceutical Research 2018; 3(4): 24-28.

DOI: https://doi.org/10.22270/ujpr.v3i4.179

Address for Correspondence:

Abbas Yazdanpanah, Department of Healthcare Management, Marvdasht Branch, Islamic Azad University, Marvdasht, Iran.

E-mail: abbas_yaz@miau.ac.ir

\section{INTRODUCTION}

Today, environment protection is one of main pillars of observing human right, so that preserving and protecting the environment is one of main duties of present and future, since the environment as an unlimited phenomenon should be protected not only for the present generation, but for continuing life of future generations. Fast increase of population, industries development, technology progress and propagation of consuming culture and as a result producing more waste are among issues that in recent decades have created great social and economic crises in human societies and have caused environmental pollutions and as a result engendering health and hygiene of the society individuals ${ }^{1}$. Planning for correct dispelling of waste and attention to its harmful impacts on the environment in any country is one of main and necessary principles for supplying long-term benefits and movement in the route of sustainable development. One of the most important components of sustainable development is management of wastes that this management requires creation of necessary grounds and plans $\mathrm{s}^{2}$. The problem of increasing waste production is very serious and for this reason, correct management of waste is in priority due to its significance and this topic has been acknowledged by many governments. One of necessary infrastructures is regulations, instruction and guidelines for management systems of urban waste. Generally, we may state that lack of rules in management systems of urban waste may cause inefficiency of urban waste management. Based on a study by World Health Organization, inattention to correct collection and disposal may provide several environmental problems that encountering them is not easily possible. In other words, increasing the population of world has created problems like waste 
for countries especially third world countries and lack of correct waste management, makes the environmental issues more and more problematic. Regarding the close relation of health and development in all societies especially in urban societies and the effective role of systematic collection and disposal of wastes is necessary in promoting cities environment health status. The present status of civil waste management and factors effective on promoting indicators of collecting and disposal of cities wastes have been investigated and its executive strategies were specified. In urban environments, despite differences that these regions have in respect of life style with civil environment, due to change in people lifestyle; waste management is discussed as an important issue. Environmental pollutions and as a result endangering of health and hygiene of citizens requires suitable pattern of waste management based on the existing conditions $^{3}$. Despite attempts of governments and international organizations, primary health requirements of the world deprived people have not been yet fulfilled. In many countries, less than $60 \%$ of cities people access to health services. One of important cases in providing health services is the problem of collecting and carrying waste and its healthy disposal. Non-healthiness of the environment of some cities of the country, existence of poverty in these regions, lack awareness of reasons of creation of diseases through urban wastes, lack of health services relating to wastes produced in cities, shortage or lack of a comprehensive system for collecting, carrying and disposal of wastes in cities and have caused an unsuitable and non-healthy environment in the cities. On the other hand, the problem of pollutions existing in the earth and many environmental difficulties is a part of problems due to inattention imposed on our life and its reflection is towards us. Familiarity with method of waste production in deprived regions of a country and controlling these waste materials is a kind of battle with these disorders ${ }^{4}$. Existence of millions tons waste in the country urban regions and ten thousands types of toxic and dangerous materials in them which is the results of human daily activities, causes wide pollutions in these environments where these waste materials produced in cities have caused 60 to $90 \%$ of various cancers directly and indirectly. There is no difference between city and village in non-healthy disposal of wastes and dangers due to it; even we may say that in some aspects cities are more noticed. Small cities like big cities don't have an integrated system like municipality which undertakes the duty of managing wastes or they are not strong enough. Public income of small cities is not as much as big cities and management of urban wastes requires more support of the government ${ }^{5}$. Due to scattering of cities, management of urban waste has its special complexities, so for economic justification, it require implementation of common plans. Generally, the significance of collecting, healthy disposal and recycling of wastes in urban regions will be clear for everybody that dangers due to it are well identified, wastes not only cause illness, putridity and environment inelegance, but also may create many damages in social life cycle by polluting soil, water and air. Therefore, regarding the above factors following problems accession in this ground, investigation of waste management for protecting safety, health and environment of Kazeroon City is inevitable. In this study, for codifying a suitable strategy for waste management in Kazeroon city SWOT model has been used and then attraction of determined strategies has been specified and prioritized using qualitative strategic planning matrix ${ }^{6}$.

\section{METHODS}

This study is of descriptive -survey type. The statistical population of this study constitutes Kazeroon City residents.

\section{Sampling method}

In this study, using Cochran formula $(\mathrm{p}=0.5, \mathrm{q}=0.5$, $\mathrm{z}=1.96, \mathrm{~d}=0.05$ and $\mathrm{N}=10709$ ), its statistical sample number was determined $326^{7}$.

$$
n=\frac{N \dot{Z} \cdot p q}{N d+Z \cdot p q}
$$

\section{Data collecting too}

In this study, the required information in the field of literature of the topic was obtained with library method and using available books and articles. Study data was collected using questionnaire in statistical sample of 400 residents of Kazeroon city. For data analysis, using descriptive statistics indicator, data were categorized, then with the aid of averages, views about respective items in every part of the descriptive table has been adjusted. Finally, with the aid of SWOT technique, respective strategies were extracted and analyzed ${ }^{7,8}$.

\section{RESULTS AND DISCUSSION}

Data obtained from interview and other collected information was used for analysis of strengths, weaknesses, opportunities and threats of the studied organizations in human resources respect in the form of SWOT model. $56.7 \%$ of studied people were men and $43.3 \%$ of them are women. $33.1 \%$ was from age group 25-30 years old, $37.5 \%$ between $31-40$ years and $29.4 \%$ in age group between $41-50$ years old. $40.44 \%$ of people had guidance school education, $39.3 \%$ had diploma, $18.9 \%$ bachelor's degree and $1.4 \%$ higher educations. $10 \%$ of people were workers, $6.2 \%$ farmer, $37.2 \%$ housewife, $2.7 \%$ unemployed and $44 \%$ were self-employed

\section{Data analysis using SWOT model}

In this section of the study, strengths, weaknesses, opportunities and threats are provided based on data obtained from interview, studying available library documents and observations based on SWOT model.

a. Identifying factors effective on environmental dangers and waste management

In this study, at first environmental factors including internal environment factors (strengths and weaknesses) and external environment factors (opportunities and threats) are investigated and identified. For this purpose, at first the existing variables in external and internal environments were identified. The factors identified in Kazerron city have been provided in Table 1 respectively ${ }^{9}$. 
Table 1: Qualitative strategic matrix (QSPM) of waste management.

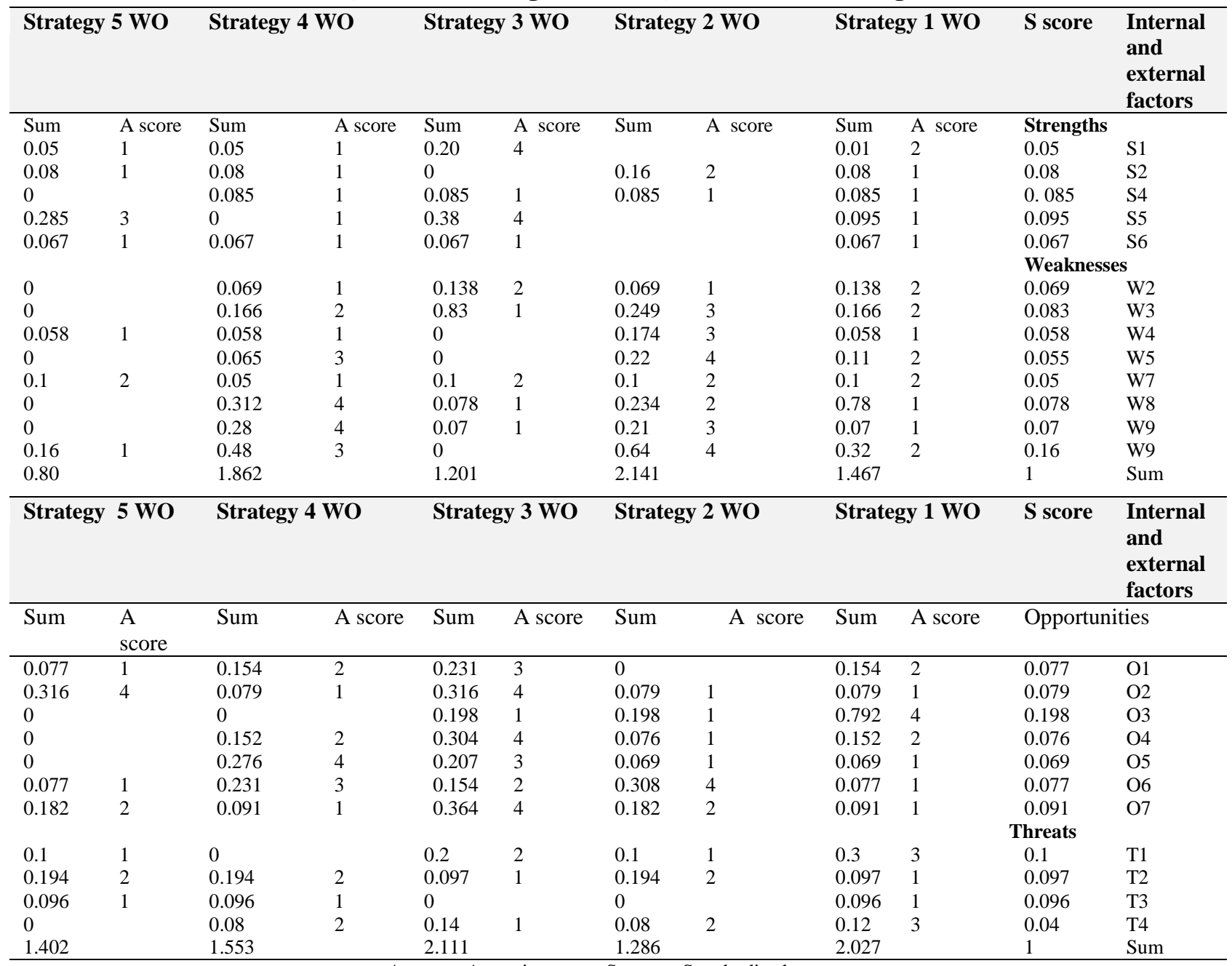

A score $=$ Attraction score, $\mathrm{S}$ score $=$ Standardized score

b. Formation of matrix of evaluating internal and external factors (EFE, IEF)

In this stage, at first those factors that in view of sample population of the study obtained average less than 3 from 5- option Likert range, were excluded from the list (that is, factors that couldn't acquire a score higher than average) and for the rest factors, EFE and IEF matrixes have been formed. Then, from 23 internal factors, 13 factors and from 17 external factors, 11 factors accepted by the society were studied. So, at first strategic factors were evaluated and insignificant factors were specified and prioritized. For evaluating internal and external strategic factors, EFE and IEF matrixes are used. After identifying internal and external factors, weaknesses, strengths, opportunities and threats of waste management are specified and matrixes of internal and external factors for each of these factors, a score based on significance of each of these factors in waste management of the studied region are considered. In the next stage, each factor is designated a weight factor between zero (insignificant) to one (very significant) that here normalization has been used for weight determining. The factors given to each factor indicates relative significance of it in success, ignoring whether the considered factor is considered as an internal weakness and strength of the organization, the factor which has the greatest impact in the organization performance should be given the highest factor. Then, the existing status of each factor is determined with a score between 4 to 1 (1=weak, $2=$ =average, $3=$ higher than average, 4=very good) which is called the existing status score. Therefore, the weighted score of each factor is calculated that for this purpose, each row of internal and external factors of the organization are multiplied in normalized weight and are mentioned in a new column. In this stage, sum of weighted scores is calculated. If the IFE final score of waste management is less than 2.5 , this means that waste management is weak in respect of internal factors. Also, if EFE final score of waste management is less than 2.5, confirms that waste management doesn't function well in using opportunities and confronting threats.

c. Formation of strategies matrix and approaches of waste management (SWOT)

In this matrix, internal and external factors are investigated so that strengths, weaknesses, opportunities and threats of the plan are identified in future and for better encountering with them, suitable approaches are codified. The Table 2 shows management of SWOT matrix that 5 strengths and 8 weaknesses (13 internal factors) and 7 opportunities and 4 threats ( 11 external factors) were identified and 2 aggressive strategies, 5 conservative strategies, 3 competitive strategies and 4 defensive strategies were categorized in the form of waste management 
strategies $^{5}$. In the next stage, by analyzing the results obtained from the evaluation of internal and external factors and by creating planned strategies, for estimating scores of each selected strategies from present situation matrix of the organization (IE) and their priority, QSPM matrix is used.

Table 2: Prioritizing strategies.

\begin{tabular}{|c|c|c|c|c|}
\hline $\begin{array}{l}\text { Sum of score } \\
\text { of strategies } \\
\text { attraction }\end{array}$ & $\begin{array}{l}\text { Attraction } \\
\text { score of } \\
\text { external } \\
\text { factors }\end{array}$ & $\begin{array}{l}\text { Attraction } \\
\text { score of } \\
\text { internal } \\
\text { factors }\end{array}$ & Conservative strategies (WO) & \\
\hline 3.494 & 2.027 & 1.467 & $\begin{array}{l}\text { Training considering their education for preventing creation of ugly } \\
\text { landscapes and non-informing them about economic value of wastes }\end{array}$ & 1 \\
\hline 3.427 & 1.286 & 2.141 & $\begin{array}{l}\text { Using day technology and trash bin for preventing wastes plurge by } \\
\text { animals }\end{array}$ & 2 \\
\hline 3.312 & 2.111 & 1.201 & $\begin{array}{c}\text { Using organic materials existing in wastes for producing agricultural } \\
\text { fertilizer and as a result job creation }\end{array}$ & 3 \\
\hline 3.415 & 1.553 & 1.862 & $\begin{array}{c}\text { Designating required credits regarding significance of the environment } \\
\text { and existing environmental rules }\end{array}$ & 4 \\
\hline 1.842 & 1.042 & 0.80 & $\begin{array}{l}\text { Increasing occupational opportunities due to investment of private } \\
\text { section in waste management }\end{array}$ & 5 \\
\hline
\end{tabular}

d. Formation of present situation matrix (internal and external factors) of the organization (IE)

In this matrix, IFE includes horizontal axis (X) and vertical axis (Y). The crossing of two axes shows present situation and objective strategies. In this sage, strategies were accommodated using instruments like SWOT matrix and internal and external matrix (IE) so that strategies are identified which are consistent with the organization goal and proportionate to its factors.

In four sections internal and external matrix, scores of matrixes of evaluating internal and external factors are determined in a two-part range of strong (2.5 to 4$)$ and weak (1 to 2.5). Regarding that based on SWOT framework, four categories of approaches (SO, ST, WO and WT) are determined for the organization and the obtained position in internal and external matrix, the emphasized region of strategies is specified in SWOT framework.

In the four-section matrix which is shown in the Table 2 , based on the scores obtained from evaluation of internal and external factors is 2.797 and 2.485 respectively. And the organization is located in conservative situation of internal and external matrix. That is, the meeting of these two axes has been located in the conservative strategies situation (WO). This means that the region has suitable weaknesses and opportunities. For developing waste management, conservative strategies should be selected and its triplet strategies are qualitatively analyzed ${ }^{3}$.

h. Formation of qualitative strategies matrix (QSPM)

In this method, at first major external opportunities and threats, external weaknesses and strengths in the right column of qualitative planning matrix have been written, then each of these internal and external factors which have a main role in the organization success, are given a weight or factor. These factors are just like factors of matrixes of internal and external factors evaluation. In the above row of matrix of strategic planning, the strategies determined by present situation matrix of IE organization and SWOT matrix are written. In the next stage, the attraction scores are determined. For determining the attraction score, internal and external factors which have a major role in the organization success are investigated and then this question is posed about each of them that if these factors have a major role in selection of strategies. If the answer to this question is yes, then we should compare the strategies with each other considering these key factors so that the relative significance of a strategy to other strategies is specified. The attraction score is in this form $1=$ without attraction, $2=$ somehow attractive, 3=attractive and reasonable, 4=very attractive). If the answer to the above question is no, it indicates that in the process of selecting strategies, this factor has no significant role (in respect of the strategy situation) that in this case, this factor shouldn't be given attraction score. In the next stage, the attraction scores are summed up, in this form that the factor in attraction scores is summed up. Sum of attraction scores indicates that it is the relative attraction of each of strategies that is obtained just regarding the impact of respective internal and external factors. The more is the sum of attraction scores; the discussed strategy will have more attraction ${ }^{6}$. Finally, sum of attraction scores of each of qualitative matrix columns is enumerated. With this method, different strategies are simultaneously investigated and prioritized. The above scores indicate more attraction of strategies. In the process of qualitative strategic planning, various strategies are investigated and their best are selected. Mentioning this point is significant that the best strategic decisions are not necessarily confirmed by decision makers, even these decisions may face with severe aversions. Based on the above table, it was specified that in the section of the internal factors of strategy of using new trash bins for preventing from wastes splurge in the city by animals with attraction score of 2.141 and the external factors section of the strategy of using organic and recyclable materials existing in the waste for producing agricultural fertilizer and as a result creating income and job creation and urban sustainable development with attraction score 2.111 in the first priority. Finally, after specifying the attraction rate of strategies using QSPM analytical method, the strategies are prioritized ${ }^{4}$.

The results of qualitative strategic matrix QSPM show that among 5 selected conservative strategies, the 
highest attraction relating to training citizens and villagers regarding their trainability for preventing ugly landscapes and informing them about economic value of wastes, with score 3.494 and the lowest attraction related to the strategy of increasing occupational opportunities due to investment in private sector in waste management has been 1.842 .

\section{CONCLUSION}

In urban environments, despite existence of differences that these regions have with industrial environments in respect of life style, due to change in people life style, waste management is discussed as a significant issue. Environmental pollutions and as a results endangering health requires suitable pattern of waste management based on existing conditions. In this plan, at first environmental factors were investigated and identified. For this purpose, at first the existing variables in the internal and external environment were identified. So, strategic factors were evaluated and important and trivial factors were specified and prioritized. For evaluating external and internal strategic factors, IFE and EFE matrixes were used. In the following, SWOT matrix was constituted and by its analysis, possible strategies were identified. For simultaneous analysis of external and internal factors, an instrument called IE matrix was used and for taking suitable decisions for selecting the QSPM strategy option shows that threats may be turned to opportunity and weaknesses to strengths using strengths in waste management. It should be said that the strategies priority order based on their general weight rate is for revision towards sustainable development. And media advertisement and society awareness about pollution due to wastes and better implementation of it has higher attraction. Strategies obtained from SWOT model indicates that requirements in the field of waste management regarding existing threats and opportunities are often very high and distribution and designation of facilities in this field regarding available opportunities and high weaknesses seems necessary. In the internal factors evaluating matrix (weakness and strength), sum of final scores was calculated 2.485 that this shows that strengths are less than weaknesses. This means that waste management in respect of internal factors has some weaknesses. The matrix of evaluating external factors (threats and opportunities) with total score of 2.797 indicates that in the existing status, waste management could act by reinforcing opportunities against threats.

\section{AUTHOR'S CONTRIBUTION}

The manuscript was carried out, written, and approved in collaboration with all authors.

\section{CONFLICT OF INTEREST}

The authors declare that they have no competing interests.

\section{ACKNOWLEDGEMENTS}

The authors extend their thanks and appreciation to the Islamic Azad University, Marvdasht, Iran to provide necessary facilities for this work.

\section{REFERENCES}

1. Saffari A. Analysis of Environmental Hazards and Rural Waste Managerial Strategies Case Study: Central Ojarood, Germy County. Space Economy and Rural Development 2013; 3:3

2. Abdoli M, Elahi A. processing and Recycling Features of Rural Waste (Case Study: Iran). Quarterly J Ecology 2010; 37(55): 105-112.

3. Timilsina, Bishnu Prasad. Public and private sector involvement in municipal solid waste management: an overview of strategy, policy and practices. A J Environment 2001; 6(7): 68-77.

4. Ghanbari M, Hesam M, Nadafi K. Study of waste management status of cities covered by health care homes in the East Azarbaijan province. Study of the waste management status of cities covered by health care homes in the East Azarbaijan province, 2013.

5. Sarmad Z, Bazargan A, Hejazi A. Research Methods in Behavioral Sciences. Publishing House Agah 2011.

6. Somayeh H, Fatemeh B, Yazdanpanah A. Evaluation of factors affecting efficiency and effectiveness among staffs of Shiraz University of medical science. Universal J Pharm Res. 2018; 3(1): 1-6. https://doi.org/10.22270/ujpr.v3i1.R1

7. Yazdanpanah A, Amiri A, Jeihooni AK. The relation between general health and organizational performance in personnel of Shiraz city emergency in 2017. Universal J Pharm Res 2018; 3(1): 25-30. https://doi.org/10.22270/ujpr.v3i1.R5

8. Jeihooni AK, Kazemi M, Yazdanpanah A. Determining the impact rate of triage training on awareness and skill level of pre-hospital emergency personnel of Fasa city. Universal J Pharm Res 2018; 3(1): 56-62.

https://doi.org/10.22270/ujpr.v3i1.R11

9. Hessam S, Simi A, Yazdanpanah A. The evaluation of the position of health and safety system in multi-level strategic management of staffs in Shiraz University of medical science. Universal J Pharm Res 2018; 3(1): 12-16. https://doi.org/10.1016/j.ssci.2016.07.002 